\title{
Preservice Elementary Teacher's Thinking about Algebraic Reasoning
}

\author{
Walter F. Castro Gordillo ${ }^{1}$, Juan D. Godino ${ }^{2}$ \\ ${ }^{1}$ Mathematics Education, School of Education, University of Antioquia, Medellin, Antioquia, \\ Colombia \\ ${ }^{2}$ Mathematics Education, Graduate School of Education, University of Granada, Granada, Spain
}

\begin{abstract}
This paper reports on the results of a research about the comprehension of elementary algebraic reasoning exhibited by preservice elementary teachers. Such comprehension is studied by means of the elementary algebraic tasks that preservice teachers propose to be worked out by primary pupils, as well as their conceptions about including elementary algebraic reasoning in primary school curriculum. Based on the analysis of the tasks it stands out the procedural and numerical conception exhibited by the preservice teachers. Additionally they conceded little importance to the relational aspect of the equal sign. Some implications for teacher education are discussed.
\end{abstract}

Keywords: Early Algebra, Preservice Teachers, Algebraic Reasoning, Conceptions on Early Algebra

\section{INTRODUCTION}

This article reports a study whose purpose was to investigate and to describe the comprehension and conceptions about elementary algebraic reasoning that preservice teachers exhibit during the design of a didactical unit. The preservice teachers' written work as well as their argumentation revealed their conceptions about elementary algebraic reasoning and the type of tasks that they foster.

Based on the preservice teachers proposed tasks, a categorization was carried out and implications will be drawn for the education of primary teachers in order to "algebrafy" (Kaput, 1998) primary mathematics curriculum. Some researchers (Carpenter, Franke, \& Levi, 2003; Kaput, 1998) have contended that the study of algebra should begin as soon as possible in the elementary school. It is believed that early exposure to algebraic ideas through curriculum could ease the transition from arithmetic to algebra due to the fact that aspects such as equality, equivalence, the sense of operations and generalization are studied early at the school.

In the context of research on elementary algebraic reasoning there are two questions posed (Carraher \& Schliemann, 2007, p. 675): can young students really deal with algebra? and, can elementary school teachers teach algebra? The research results in the field of elementary algebraic reasoning respond affirmatively to the first question and point out the children's mathematical achievements when working on elementary algebraic tasks (Carpenter, Franke \& Levi, 2003; Carraher, Martinez \& Schliemann, 2008).

The inservice teachers performance when dealing with elementary algebraic tasks have been studied (Borko, Pittman, Eiteljorg, Nelson, \& Jacobs, 2005; Jacobs, Franke, 
Carpenter, Levi, \& Battey, 2007; Asquith, P., Stephens, A., Knuth, E., \& Alibali, M., 2007; Blanton \& Kaput, 2005; Stephens, 2008); nonetheless, scarce research evidence on the performance of preservice teachers when dealing with elementary algebraic reasoning is available.

Taking into account this research context, there is the need to investigate on the comprehension about elementary algebraic reasoning exhibited by preservice elementary teachers. Specifically, we are interested in preservice teacher's competence to identify and to propose mathematical tasks related to algebra in the elementary school. The paper is organized in five sections; the second one describes our approach to the elementary algebraic reasoning and its relation to other approaches to interpret such reasoning. In the third section, the research method is explained; in the fourth one, the preservice teachers' comprehension and conceptions are exhibited and commented. Finally, some implications for the preservice teachers' education are offered.

\section{An Approach to Elementary Algebraic Reasoning}

Some researchers have proposed diverse conceptualizations about algebraic reasoning in elementary school (Burkhardt, 2001; Blanton \& Kaput, 2001). Burkhardt (2001) proposed a partly research-based taxonomy of algebraic performance that includes fifteen aspects. Some of them are: inverting functional relationships; constructing general symbolic proofs; formulating procedural programs constructing linked spreadsheets, etc. We consider that four features of this taxonomy could be included in a curricular proposal for algebra in primary school: Extending number and geometric patterns; formulating verbal rules for stepwise patterns extensions; substituting numbers in formulas, evaluated with calculators and finally; formulating verbal rules for functional relationships, or explanations for general results. The remaining aspects are linked to secondary algebra.

This research is in the context of social practice developed by teachers, it takes into account notions such as practice, object and mathematics process introduced by the "ontosemiotic approach" to cognition and mathematical instruction (Godino, Batanero \& Font, 2007). According to the context where this research took, preservice teachers designing a didactic unit, we consider as "elementary algebraic reasoning" the system of operative and discursive practices put into effect during the resolution of school mathematical tasks where algebraic objects and processes intervene (symbolization, relation, variables, unknowns, equations, patterns, generalization, modelling, etc).

\section{METHOD}

\section{The Context}

The research was conducted in the frame of a Mathematics Method course for teachers (taught at School of Education of University of Granada) that includes both a practical and a theoretical component. The design of the course included, among other tasks, the elaboration of a "didactical unit" on a primary school mathematical topic. It was in the context of the elaboration of the didactical unit that the students chose the topic on algebraic reasoning for the fifth grade. It is worth mentioning that neither the content knowledge of algebra nor its didactics was studied in the Mathematics Method course.

\section{Procedure}

The objective of this research is to examine the comprehension about elementary algebraic reasoning exhibited by preservice teachers while designing a didactical unit on algebra at the elementary school. Our questions are oriented toward the determination of what the preservice teachers consider algebra in the elementary school, the type of tasks that would propose to children, the algebraic aspects identified in the proposed tasks and 
the justification the preservice teachers use to include the mathematical tasks in the didactical unit.

The first author offered to counsel the teams, and a total of seven four-student teams chose to work the didactical unit about algebraic reasoning in the fifth grade of primary school. At the beginning of the academic term, students were informed on the more frequent difficulties related to both the use of letters and the equal. Additionally, a practice using exercises adapted from Booth (1984) were done with the preservice teachers.

In order to achieve the research objectives, some freedom of action was offered to the preservice teachers, so they chose: the number of working sessions, the elementary mathematics textbooks, the tasks to be discussed during the working sessions. They decided which tasks to include in the final version of their didactical unit. During the working sessions, the first author guided the teams toward the complementation of conditions on the design of the didactical unit. Additionally, they discussed on the solution of the tasks, the "algebraic" nature of them and posed questions on the difficulties that pupils could face when solving the tasks.

The preservice teachers were invited both to reflect on the conflicts of mathematical nature that could emerge during the resolution of tasks by pupils and to debate on such conflicts. The preservice teachers took decisions not only on the inclusion of the tasks and on its algebraic character but also on the linguistic elements, concepts, procedures, properties and arguments that are put into effect during the resolution. It is worth mentioning that a great effort was invested in the discussions to be held in the frame of our approach to elementary algebraic reasoning. The research was conducted during the first quarter of the 2009-2010 academic year. An average of five meetings ranging from sixty to ninety minutes was held with every group.

\section{Analysis of the Data}

The research was conducted with a group of 28 preservice teachers, aged 20 years on average. The group was composed by 80 percent women and 20 percent men. The preservice teachers manifested a great affinity to education; some of them manifested having some experience in tutoring children. The preservice teachers showed interest in algebraic reasoning in elementary school because "it is not possible to teach algebra in [primary] school... We want to know what it is all about" (as expressed by one to the preservice teachers). During working sessions the preservice teachers manifested a critical and independent thinking.

\section{Data Collection}

In order to get a comprehension of the process underwent by the preservice teachers, a triangulation process was done and various data sources were used: written solution of tasks, written identification of algebraic elements, informal conversations, initial didactical unit drafts and final versions, audio and video of the working sessions.

The data analysis was carried out in two stages. The first one took place along the study itself with the analysis of the working sessions, the study of tasks proposed by the preservice teachers as well as their questions and reflections. The second stage started shortly after the course ended and the preservice teachers handled out and presented their didactical units. The audios, videos and written preservice teachers' work were codified and conceptual categories were searched for. An interview was held with every team two months after academic term ended to discuss about some issues related to their didactical units.

\section{Categories Identified of Tasks}

Once the tasks were analysed, thirteen types of tasks were identified (Table 1). We found that five groups of tasks were "letter oriented", and five groups were "problem oriented"; the 
remaining three were grouped in accordance to the preservice teachers proposed criteria. The first category reminds the letter algebraic features identified by Kücheman (1981), while the second is related to Burkhardt's proposal (Burkhardt, 2001). In order to validate the findings we conducted interviews with the preservice teachers' teams. Table 1 shows the categories of tasks grouped according to the criteria.

Table 1.Categories of tasks proposed by the preservice teachers

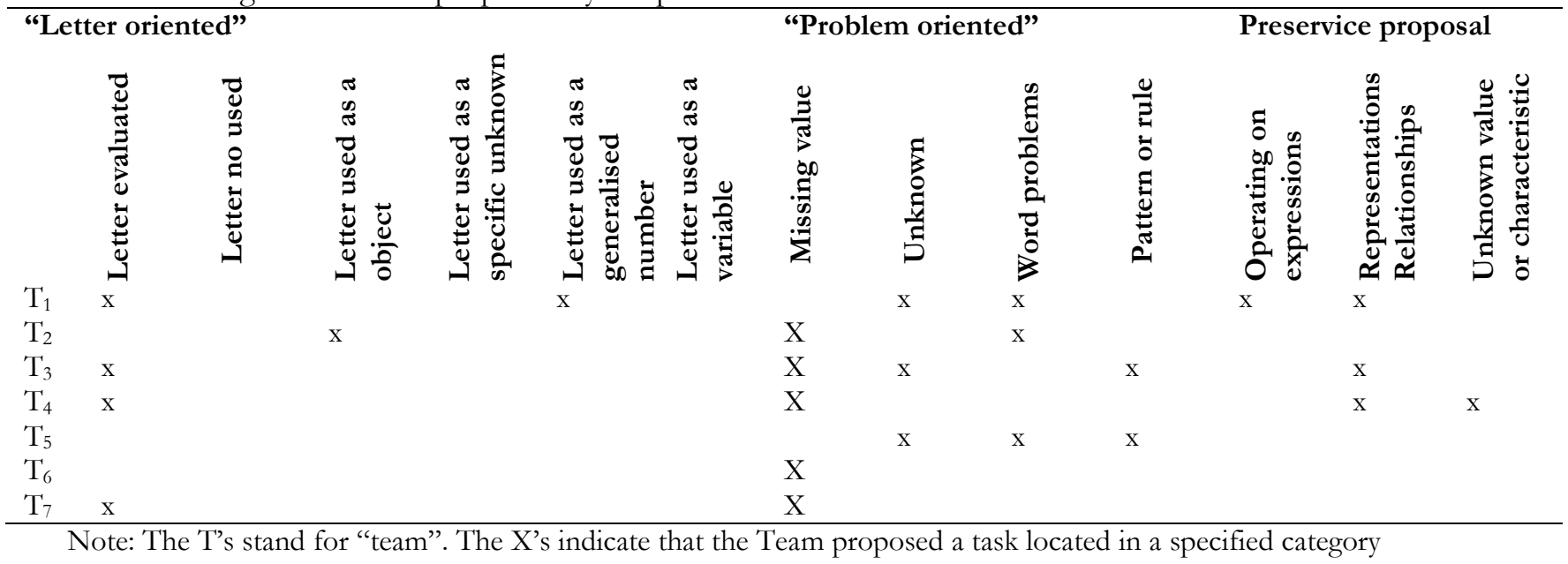

\section{Comprehension and Conceptions}

We will exhibit a task corresponding to each one of the thirteen categories and they will be discussed in the context of elementary algebraic reasoning. We will also include some audio transcripts to show the preservice teachers reflections during working sessions. The preservice teachers' reflections allow us partially inferring their conceptions on elementary algebraic reasoning.

\section{Categories Corresponding to First Criterion}

Letter evaluated: the letter can be evaluated immediately, its value can be determined directly. The majority of the preservice teachers' proposed tasks for this category are geometry related; one of such tasks is:

Michel wants to put a circular fence having a $2 \mathrm{~m}$ radius. What is the longitude of the fence?

The solution given by preservice is:

The fence longitude is: $L=\pi \times 2 r=3,14 \times 2 \times 2=12,56 \mathrm{~m}$

The preservice teachers usually favour the numerical procedure over the geometrical concepts that have to be recognized for a significative use of the formula.

Object: the letter is regarded as shorthand for an object or as an object in its own right. The preservice teachers' experiences with secondary algebra make them to consider letters as abbreviations for objects. Clement (1982) and Kieran \& Chalouh (1993) have pointed out that such experiences sometimes lead to letter use with meanings different from those used in algebra. In arithmetic children experience the use of letters to denote measures, for instance, $5 \mathrm{~m}$ denote 5 meters, nonetheless, in algebra $5 \mathrm{~m}$ can denote five times an unspecified number.

Kücheman (1981) reports that the expression $(2 a+5 b+a)$ is interpreted by children as an abbreviation that denotes two apples and five bananas and another apple; evidence that $a$ and $b$ are interpreted as apples and bananas instead of number of apples and bananas respectively.

The same interpretation is expressed when the preservice teachers solve some word problems. In Fig. 1 the first part of the resolution of the following problem is shown: 
If the combined cost of two umbrellas and one peaked cap is 80 euro, and the combined cost of one umbrella and two peaked caps is 76 euro; how much is the cost of one peaked cap and one umbrella?
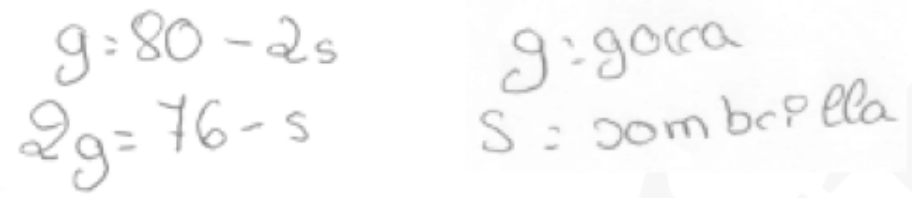

Figure 1. Word problem solution

It is observed that "g" and " $\mathrm{s}$ " are interpreted as caps and umbrellas (gorras and sombrillas respectively in Spanish) in the same sense reported by Kücheman (1981); however this seems not to affect the resolution process carried out by the preservice teachers, whose answer is given in terms of the cost of one cap and one umbrella. It could be hypothesized that the preservice teachers use an implicit criterion that accepts the coexistence of letter as object and letter as unknown, but somehow they "control" the unknown, letting them providing the right answer to the problem, stating both the numeric value and the name of the unknown, that corresponds to the numeric value under investigation.

Another team of preservice teachers proposed a task that makes an "extended" use of Kücheman's definition, in the sense that letters are used as a reference to numbers location.

The task is: "Locate the given number where it corresponds: 1456". The task is accompanied by the table:

\begin{tabular}{|c|c|c|c|c|c|}
\hline HTh & TTh & UTh & Th & T & U \\
\hline & & & & & \\
\hline
\end{tabular}

Where HTh, TTh, UTh, Th, T and U stand for: hundreds of thousand, tens of thousand, units of thousand, thousand, tens and units, respectively.

Letter as a generalized number: the letter is seen as representing, or at least able to take, several values rather than just one. One of the tasks, proposed by the preservice teachers, that fits in this category is the following:

Change the letters by numbers from 1 to 16 in such a way that summing them up in any direction, the result be 34

\begin{tabular}{|l|l|l|l|}
\hline$A$ & 3 & $B$ & 13 \\
\hline 5 & 10 & $C$ & $D$ \\
\hline$E$ & 6 & 7 & $F$ \\
\hline 4 & $G$ & $H$ & 1 \\
\hline
\end{tabular}

Considering the set of tasks proposed by the preservice teachers, only three correspond to letter as generalised number. None of the teams proposed tasks either for "letter not used" (children ignore the letter) or for "letter used as a specific unknown". According to the interviews carried out two months after the term ended, the preservice teachers consider that children should operate with letters or replace them by numeric values, and not to ignore them at all.

A segment that illustrates the preservice teachers' stance is the following:

E11: The students should work with letters, replace them with numbers or find the solutions in equations. But these exercises [replacing letters by numbers] are to much easy; algebra is a little bit more complex, such as finding unknown values, solving equations... come on... solving problems.

The preservice teachers did not propose any tasks for the category "variable", this could be so due that Spanish Curricular Standards (MEC, 2006) ${ }^{2}$ does not include this concept to

\footnotetext{
${ }^{1} \mathrm{E} 1, \mathrm{E} 2, \mathrm{E} 3$, etc, stand for students, and R stands for researcher.

${ }^{2}$ MEC (2006). Royal Decree 1513/2006 that establishes the content for Primary Education. BOE number 293.
} 
be taught at elementary school. Additionally, the preservice teachers themselves could experience difficulties identifying, using and solving mathematical tasks that involve the concept of variable. Asquith et al., (2007) report that secondary school teachers experienced difficulties solving some algebra problems regarding the use of variable, as well as predicting on pupils difficulties and responses to variable tasks. It is possible that the same misunderstanding be shared by the preservice primary teachers.

\section{Categories Corresponding to Second Criterion}

Missing value: value or values missing, they have to be found using some arithmetic procedures. This category collects the majority of tasks proposed by preservice teachers. One of the aforementioned tasks is: "complete and calculate: _ _ $x 38=5396$ ".

Table 2 shows types of tasks grouped according to: operations used and quantity of missing values- one or two-. The sub index stands for the team that proposed the task.

Table 2. Missing value tasks

$\begin{array}{lllll}\text { Sum Subtraction Product } & \text { Division } & \text { Division algorithm } & \begin{array}{l}\text { Multiplication } \\ \text { algorithm }\end{array} & \text { Exponents }\end{array}$

Various missing values

$\begin{array}{ll}\mathrm{X}_{\mathrm{G} 2} & \mathrm{X}_{\mathrm{G} 2} \\ \mathrm{X}_{\mathrm{G} 3} & \mathrm{X}_{\mathrm{G} 7}\end{array}$

Unique missing value

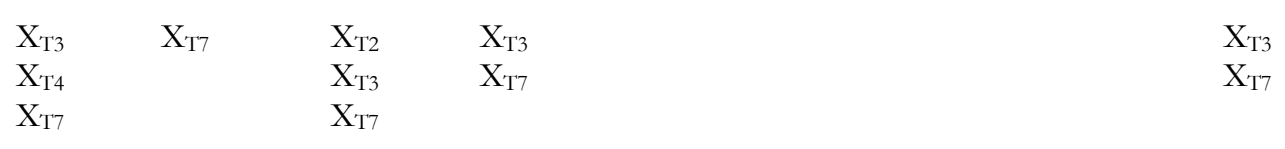

The total number of tasks on this category corresponds to arithmetic equations. The arithmetic interpretation (Rojano, 1988) of the equal sign as a result is enough to solve them all. As a matter of fact, one of the teams only proposed missing value tasks with natural numbers, integers and with decimals up to two figures.

The following segment shows the stance of these team's members in regard to their choosing of this type of tasks as including elementary algebraic reasoning.

$R$ : Why do you believe this exercise that reads "calculates the missing term" is an elementary algebraic reasoning task?

E2: Even though letters are not present, an unknown is present, a blank space does not look like a letter... but you have to find out what is missing using an operation, a division or something and based on it you have to find out the blank space that depends on how you want to put it; but instead a hole you can put a letter as well.

The lack of algebraic equations that use the relational interpretation of the equal sign could be explained by the difficulties and deficiencies exhibited by the preservice teachers themselves and that could be the same reported by Herscovics \& Kieran (1980) and Knuth et al., (2006) by the inservice secondary school teachers.

The equations whose missing value corresponds to an exponent broaden the type of arithmetic equations that could be solved in elementary school (Rojano, 1988; Filloy \& Rojano, 1989) because a new type of equations could be added up: the exponential numeric equations. An interesting type of missing value task is those where some unknown values have to be found by resorting to a profound knowledge of division and product algorithms. This type of tasks is proposed on primary mathematics textbooks.

Not known values of characteristics: unknown value or values represented by letters ad that have to be found following some problem restrictions. A task on this category is:

$$
\text { Carry out the following sum: } b a 8+42 a+a b 4=1 a 15
$$

This task raises some interesting issues to consider; the first one is the wording of the problem instructions, the preservice teachers ask to find out the result of the sum, but in 
fact what they want pupils to find are the letter values for the equality to be valid. The second one is that the concatenation among numbers and letters has to be interpreted by pupils in terms of the positional system and in no way as a not specified product. It is to highlight the "algebraic" metonymy spontaneously used by students.

The third one is that the sum must be performed but it is already done; it seems that the preservice teachers consider the operation as not closed and it is the lack of closure (Kieran, 1981) what compels looking for numeric values that have to be assigned to letters. The fourth aspect is related to the relational meaning of the equal sign, stressed by Subramaniam \& Banerjee (2004) that permits solving the problem but that it is not recognised by the preservice teachers.

The fifth one is that the procedure implemented to solve the problem uses the sum algorithm and requires solving a set of nested linear parametric equations, one of them is: $8+a+4=t 5$, where the parameter $t$ takes values in the set of digit numbers. The solution process reminds the simplex method (Sinha, 2006) used in linear programming.

Neither the difficulty of this type of tasks nor the opportunities they offer to discuss some aspects of elementary algebra are recognized explicitly by preservice teachers in their planning of the mathematical task. In general terms, it seems that they have reached certain level that allows them identifying some algebraic aspects that can be discussed with children. Nonetheless, their preference of certain meanings without any justification or specifying reveals some degree of unawareness on the complex web of related conceptual and procedural aspects that characterises the algebraic reasoning (Blanton \& Kaput, 2005, p.414).

Word problems: solution of word problems, which could include numeric or algebraic processes. One of the tasks proposed was:

A bus leaves Small Ville with certain quantity of passengers, in the first stop step down 4 passengers, in the second get in 12, in the third one step down 7, in the fourth one step down 9 and finally arrived 14 at the last stop. How many passengers were in the bus when it left Small Ville?

The task is considered by the preservice teachers as algebraic because it can be solved using a linear equation, method used by the preservice teachers to solve the task.

The preservice teachers state at the beginning of the resolution process, designed to be explained to pupils: "We have an auto bus with an unknown quantity of passengers to which we name as A", then the preservice teachers translate each sentence in the problem's wording into an algebraic expression:

In the first stop four passengers get down, that way, the number the passenger in the bus is the number of passenger at the beginning of the trip minus four, that is to say, A-4.

The preservice teachers proceed with the solution process until they obtain the equation: A $-4+12-7-9=14$; the equation resolution process used by preservice teachers is:

$$
\begin{gathered}
A-8=14 \\
A=22
\end{gathered}
$$

Finally, they affirm: "The bus left Small Ville with 22 passengers".

The arithmetic-algebraic word problems have been largely studied both in curricular (Bell, 1996) and cognitive fields. Some authors have studied the word problems in the transition process from arithmetic to algebra (Bednarz \& Janvier, 1996; Filloy, Rojano \& Rubio, 2001; Puig \& Cerdan, 1990). Puig \& Cerdan (1990) consider a word problem as arithmetic or algebraic in terms of the translation process; if this process leads to an expression that solely involves numeric data or by contrast, an expression that involves an unknown or an equation, the problem is said to be arithmetic or algebraic, respectively. An arithmetic problem can be solved through the analysis-synthesis method, while an algebraic one can be solved through the Cartesian method.

Assessed under the Puig \& Cerdan (1990) approach, the word problems proposed by preservice teachers are arithmetic. Nonetheless, the preservice teachers consider them as algebraic because they can be solved using equations. An instance of a task whose arithmetic nature stands out but nonetheless is considered as "algebraic" by the preservice teachers is: 
What is boys' favourite sport? And, what is girls' favourite sport?

\begin{tabular}{|l|l|c|l|}
\hline & Girls & Boys & Total \\
\hline Soccer & 18 & & 45 \\
\hline Sky & $\square$ & 20 & 41 \\
\hline
\end{tabular}

The preservice teachers assess it as algebraic because it can be solved using a linear equation. However, they consider that the problem can be solved using an arithmetic process without using equations. The preservice teachers' suggested method is that of "reverse" where the operations can be "undone".

Unlike Van Dooren, Vershaffel, \& Onghema (2003) who report that the strategies used by preservice secondary school teachers for solving arithmetic and algebra word problems are classified in two groups: the first one adapted to arithmetic or algebraic nature of problems whereas the second one "tended to apply exclusively arithmetic methods (which led to failures on the most difficult word problems)", p. 27. The preservice teachers in our study preferred the algebraic solution to justify the task inclusion in the didactical unit, even though they do recognized that pupils would use a numeric strategy to solve the task.

The preservice teachers state that the chosen task is intended to "introduce the algebraic notation using unknowns" and consider two untwine aspects in the solution of algebraic tasks: the translation from Spanish to algebraic language and later, from algebraic language to Spanish. Later, the preservice teachers state that the purpose of translating "phrases to algebraic language" is "to represent a given information in algebraic terms, in order to carry out a mathematical task", and vice versa "translation from algebraic language to ordinary language" because "once the mathematics is done it is necessary to 'retranslate' the solution to ordinary language in order to communicate it".

Identification of rules and patterns. The preservice teachers propose numeric tasks where they ask pupils to generalize an arithmetic principle; an instance of such a task is:

"Carry out the sum trying to get a rule. Explains your rule, tried out the operations: 175+101=276; $567+201=768 ; 685+401=1086$ "

The rule the preservice teachers refer to is: "to add up 101, 201,301... to a number, first we have to add up 100,200, $300 \ldots$ and then add up 1". It is worth mentioning that preservice teachers took a task, proposed in a text book (Anaya, 2007; p.9) and modified it by changing the text book's proposal that was to perform the sums.

The task solution requires using the associative property and generalising the rule. The operations and their properties have being located among the difficulties in algebra learning (Williams \& Cooper, 2001); additionally the pattern exploration offers opportunities to pupils to observe and verbalise (English \& Warren, 1998) that in association with generalization are considered suitable mathematical activities to introduce children to algebraic aspects (Mason, Pimm, Graham, \& Gower, 1985).

Some researchers have studied the generalization processes and the role they play in elementary algebraic reasoning; Bastable \& Schifter (2007), Schifter (1999) described instances of pupils' algebraic reasoning involving generalizations; Carpenter et al., (2003); Carpenter \& Franke (2001) and Carpenter \& Levi (2000) document pupils from elementary school discussing on generalizations of arithmetic principles. Warren (2005) reports how primary pupils can articulate generality in growing patterns in terms of their position. It can be deduced from research that pupils can discuss mathematical tasks involving generalization. Nonetheless, the preservice teachers only proposed two activities related to generalization, where validity is neither questioned nor discussed.

It seems that the preservice teachers in our study do not recognised spontaneously the generalization or quasi-generalization tasks because their conception of algebraic reasoning is based on two elements: the first one is that algebra is linked to the use of letters where numeric operations have to be performed and, the second one is that textbooks do not proposed tasks to find or to justify patterns or rules. 


\section{Categories Based on Preservice Criteria}

Numeric and algebraic representation of relations, among numbers or letters. A team proposed the following activity:

Using arithmetic operations and letters, write each one of the following statements: Robert's age is five year less that Arturo's; Anthony has 200 euro more that John; Carmen's age is ...; Marisa has three times as much money as Eva.

The preservice teachers consider that the representation of arithmetic and algebraic relations of the type "more than", "less than", "twice as much", belongs to elementary algebraic reasoning. We highlight the identification of linguistic elements, performed by the preservice teachers, whose interpretation can modify the pupils' solution process. The effect that certain key words have in the transition process from word statements to corresponding mathematical expressions has been studied by Nesher \& Teubal (1975).

The preservice teachers recognised that some language structures could affect the comprehension and solution of certain mathematical activities, and this recognition could be a sign of their own evolution in the comprehension of algebraic notation. For MacGregor $\&$ Price (1999), "conscious awareness of language structures and the ability to manipulate those structures may be the manifestation of deeper cognitive process that also underlie the understanding of algebraic notation" (p. 462).

Another team proposed the following task:

\begin{tabular}{|l|l|l|l|l|l|l|}
\hline Grades & $5 \mathrm{~A}$ & $5 \mathrm{~B}$ & $5 \mathrm{C}$ & $6 \mathrm{~A}$ & $6 \mathrm{~B}$ & $6 \mathrm{C}$ \\
\hline Number of collected toys & 160 & 90 & 130 & 140 & 120 & 90 \\
\hline
\end{tabular}

Provide an answer to each of the following questions:

a) How many toys collected each fifth grade class?, and each sixth grade class?

b) Which class collected more toys? and which class collected less toys?.

c) How many toys collected sixth grade A more than sixth grade C? How many toys collected sixth grade B less than sixth grade C?, and how many collected fifth grade B less than sixth grade B?

These two teams of preservice teachers coincide in valuing the establishment of relations "more than" or "less than" as features of elementary algebraic reasoning. The first team propose to use letters while the second one just asks to answer the arithmetic questions.

Boulton-Lewis et al. (1997) proposed to represent numbers, arithmetic operations, symbol manipulation and parenthesis in arithmetic, and stressed the relationship between arithmetic and algebraic activities. The above authors considered that the increasing cognitive demands and the recognising of relationships ease the work with unknowns and later, with variables.

It seems that the preservice teachers in keeping with research carried out by BoultonBoulton-Lewis, Cooper, Atweh, Wilss, \& Mutch (1997) consider that recognising these relationships in arithmetic foster its ensuing use in algebra; this also coincides with findings of some authors (Chevallard, 1989; Sfard, 1991) who concede importance to arithmetic knowledge as the base of algebraic knowledge.

Any unknown value in the problem. In this category are grouped mathematical activities where an unknown numeric value or characteristic has to be found.

An example to illustrate this category is:

Paula has a clothing store. Today she has issued a merchandise order consisting of 24 shirts, 15 tracksuits and 30 sport shoes. The cost of a shirt, a tracksuit and a pair or sport shoes is $19 €, 38 €$ and $42 €$, respectively. How much Paula has to pay for her merchandise order?

In the task solution, preservice teachers proposed the following procedure as an intermediate step to give the answer: 


\begin{tabular}{|l|l|l|}
\hline $\begin{array}{l}1 \text { shirt_19€_ } \\
24 \text { shirts_? }\end{array}$ & $\begin{array}{l}1 \text { tracksuit__ } 38 € \\
15 \text { tracksuits__? }\end{array}$ & $\begin{array}{l}1 \text { pair of shoes__42€ } \\
30 \text { pair of shoes__ ? }\end{array}$ \\
\hline
\end{tabular}

The preservice teacher' stance is firm in regard to the algebraic nature of this type of tasks:

R: When you propose this exercise, Paula and shirts: one shirt cost $19 €, 24$ shirts... here appears a question mark, what does this question mark stand for?

E3: Is an unknown, come on, a number we do not know and we have to find it, of course...

It can be contended that these types of tasks could be located in the group corresponding to "Unknown", Table 1, nonetheless we have acknowledge an entity of its own to this category, by the concurrence of two features identified by the preservice teachers: an unknown value or characteristic and the process to find it. This process could be not arithmetic in nature. To illustrate our point we give this example:

Three friends Peter, Anton and Paul do not agreed on their ages. Peter is older than Paul; Paul is younger that Anton; Anton is older that Peter. Who is older? Who is younger?

When the preservice teacher is questioned on the algebraic nature of this task, affirms: E3: Here we do not know the age, and as we do know the age, we could assign A to Anton, $B$ to Paul and $C$ to Peter and we already have three unknowns, because we ignore all of them, we only know what the problem states, but not the age; then we have three unknowns.

$R$ : But the problems do not ask to find the ages, just who is older and younger; we do not look for the ages; is this an elementary algebraic task nonetheless? We neither carry out number operations nor solve any equation...

E3: $\mathrm{hmmm}$, yes, it still is [an algebraic task], it does not matter that the ages are not given, we solve the problem, we find who is younger and older, you know, we solve the problem using the information given... and that is all.

The naming, by the preservice teachers, of this type of tasks as algebraic could be based in the belief that algebra deals with unknown values and with procedures to find the unknown values. Algebra is an abstract system where operations reflects arithmetic structure (Cooper, Williams \& Baturo, 1999), then a value that has to be found share the algebraic characteristics of a unknown.

Operating on expressions. One of the proposed tasks on this category is:

$$
\text { "Calculates the following expression: } a+\frac{a}{2}=\text { " }
$$

It has a strong procedural character; one member of the team that proposed the task, stated: "algebra problems are those where you have an unknown and you have to use it to calculate something". It seems that the preservice teachers, based on their experience with algebra at secondary school, consider this type of exercises which use algebraic expressions and operations, as elementary algebraic tasks. The team of preservice teachers that proposed this task exhibited certain preference for algebraic tasks that stress the symbolic procedures. This finding was also identified by Nathan \& Koedinger (2000), who informed that high school teachers tended toward a symbolic precedence view of algebra "before moving on to verbally presented problems", (p.4).

\section{Thematic Tasks Distribution}

The preservice' teachers mathematical tasks are grouped by topics in two sets: numbers and operations, and geometry. Eighty percent of tasks are related to numbers and operations, what suggest the strongly numeric character that the preservice teachers concede to elementary algebraic reasoning at school. We infer that the preservice teachers consider numbers and operations as the base of algebraic thinking. This inference agrees with the Anderson's report (2002), who states that children need more practice with arithmetic operations in order to solve numeric equations involving elementary algebraic reasoning. 
However, some researchers contend that a sound numeric knowledge is a condition to proceed from arithmetic to algebra; and consider that the emphasis on the numeric can be an obstacle to solve some algebraic tasks. In the field of numeric equations, McNeil \& Alibali (2002) have found that pupils difficulties on equation solving are justified partially due to the long exposure to arithmetic operations; according to this view "children's knowledge of arithmetic operations hinders their ability to solve novel equations", (p.884).

Linchevski \& Livneh $(1999$, p.192) states: "difficulties revealed in children's understanding of structural properties of the algebraic system originate in their understanding of the number system", nonetheless the preservice teachers in our study, consider that algebra should be located at the end of arithmetic course, because the arithmetic knowledge is a requisite to solve tasks on elementary algebra. The arithmetic precedence over algebra is put on evidence in the following segment:

E5: In planning school algebra it should be located at the end... because it is always about solving a multiplication, a sum, to name something... and right away it should have been taught all the previous [arithmetic] and then algebra.

Other segment illustrating this stance, which refers to the solution to the exercise : $53=68$, is the following:

$R:$ What is the most important concept children have to use in order to solve the task?

E6: The multiplication and division operations; algebra is something minor, students are working with multiples and divisors.

E6: The gaps [blanks] are for a change, for the children not to relate a letter to algebra, because algebra do not have to be letters... is for the children to try out what they are doing with multiplications and it is actually what the task ask for, of course, because in sixth grade equations are not taught; just because the gap is as an unknown.

It is possible that the preservice teachers' tendency to prefer the numeric and the procedural over the structural be in part motivated by text books used to prepare the didactical unit. Some researches have identified that text books shape teacher's teaching practices and curricular planning (Borko \& Shavelson, 1990; Cooney, 1985). The exploration of this hypothesis is not developed on this paper.

The percentage of tasks involving geometry corresponds approximately to $4 \%$ of the total number of tasks, and only one team proposed them. Although one of the teams proposed a task where area and perimeter were to be calculated, there is no evidence of any link between multiplication and area understanding, the emphasis is put on the use of the formula to calculate a numeric value and not in the area itself. This finding is in agreement with Simon and Blume findings (1994; p. 476).

\section{The Equal Sign}

We consider appropriate to investigate some features related to the equal sign, operations and its properties, and variable meaning (Williams \& Cooper, 2001), in the tasks proposed by the preservice teachers. Freiman and Lee (2004) have recognised the relevance of the equal sign comprehension as part of the introduction of children to algebraic reasoning. Carpenter et al., (2003) report that pre-schoolers and first graders exhibit the belief that after the equal sign the result must be located. This equal sign interpretation, as an action that has to be performed on numbers located on the left and whose result is written on the right, prevents comprehend it in relational terms. Children deduce that the equal sign means total (Behr, Erlwanger \& Nichols, 1980; Kieran, 1981).

Although during working sessions with the preservice teachers not only the procedural and relational aspects of the equal sign but also pupils' difficulties on missing value equations solving were discussed (McNeil \& Alibali, 2004 and 2005) preservice teachers did not concede much importance to the relational aspect of the equal sign; this is deduced from the lack of tasks that put into effect this equal sign feature.

The preservice teachers proposed a number of tasks where arithmetic equations have to be solved. Nonetheless, they do not recognise the difficulties faced by children when dealing with the equal sign. Tasks do not try to foster a relational view of it. This finding keeps in 
with Asquith et al., (2007) findings that report that inservice teachers rarely identify mistakes related to the equal sign as an obstacle to solve problems that required this concept to be used.

However, some preservice teachers recognized that pupils have difficulties dealing with the equal sign; the following task: $5+_{-}=8+4$, was discussed with one of the teams, and one preservice teacher said: "the boy I give classes to do not understand this [exercise]; if a number is not place before the equal sign he would not know what to do"; nonetheless, this type of tasks or questioning do not appear on preservice teachers proposed tasks.

\section{FINDINGS AND DISCUSSION}

On this paper we have investigated not only the comprehension on elementary algebraic reasoning that preservice teachers expressed while proposing elementary algebraic activities but also the conceptions about the inclusion of algebraic reasoning in primary curriculum.

Blanton and Kaput (2003) proposal to develop algebraic "eyes and ears" to algebrafy primary mathematics curriculum requires, among others aspects, that teachers not only can identify the algebraic nature of some mathematical activities but also that can recognised and foster the algebraic reasoning present in children's mathematical activity.

Although the set of preservice' mathematical tasks are large-thirteen categories-there is a strong tendency to assimilate algebraic reasoning to: finding unknown values that are associated to unknowns; symbolizing numeric relations and solving word problems. The activities stressed the procedural and numerical over conceptual features.

This finding agrees with Stump \& Bishop results (2002) who found that teacher's views of algebra "are typically derived from their experiences in middle school and high school", (p.1) that are limited, and described algebra in terms of equation solutions, finding unknown values and as a tool to solve problems.

Additionally, preservice teachers acknowledge spontaneously little importance to the equal sign, and only recognised it as a symbol indicating result. Even though during working sessions, a number of exercises requiring the relational interpretation of the equal sign were discussed, the preservice teachers kept attached to their operative conception on the equal sign.

This emphasis could be based both on conceptions, experienced during the preservice teachers' secondary school experience, that are a source of inspiration when acquired through personal experience, and on lack of attention that the equal sign receives in curricular materials available to preservice teachers (McNeil, Grandau, Knut, Alibali, Stephens, Hattikudur, et al., 2006).

The discussions held on working sessions seem not to have exerted any effect on the choice and on the questioning of key features promoting elementary algebraic reasoning, such as equal sign relational aspect and generalization, among others. Nonetheless, the possible effect that counselling had on preservice' teachers decisions are to be assessed.

\section{CONCLUSIONS AND IMPLICATIONS}

The bipolar instructional conception held by the preservice teachers: "teacher explainspupils perform", and the procedural character that they concede to algebra seems to mould the choice of mathematical tasks that are proposed and discussed.

The preservice teachers should know the research findings about both difficulties and pupils' performance on elementary algebraic tasks. Some emphasis should be put on "unpacking" (Ball, Thames \& Phelps, 2008) algebraic knowledge present in mathematic content for the preservice teachers to foster and to recognised it. Furthermore, even inservice teachers "have little experience with the rich and connected aspects of algebraic reasoning” (Blanton \& Kaput, 2005, p.414). 
Blanton \& Kaput (2005) contend that "elementary teachers [are] in the critical path to mathematics reform and, in fact, the degree to which they are capable of developing children's algebraic reasoning may determine the depth of that reform", (p.414). In order for the preservice teachers to recognise and to foster elementary algebraic reasoning in pupils, some researchers propose specific actions. McGowen and Davis (2001) propose a list of actions for the preservice teachers to change and to face their not examined conceptions on algebra. Borko et al., (2005) propose a teacher professional development program that focuses on cultivating teachers' understanding of algebraic thinking, learning, and teaching focused on the conceptual framework of community of learning and on the cooperative learning environment. Asquith et al., (2007) state that "professional development efforts are needed that focus on connections between what has been considered the domain of arithmetic (such as learning about the equal sign and developing number sense) and the algebra learning occurring in middle school" (p.269). Stephens (2008) considers that "such connections might help teachers think about algebra as a way of thinking as opposed to a list of procedures to be followed", (p.45). This might contribute to the expansion of students experience with algebra.

Based on our findings we considered that opportunities have to be offered to the preservice teachers for them to expand their algebra conception beyond the focus on symbols and symbolic manipulation. One of such activities might be the didactic analysis that favours to highlight not only the web of concepts and meanings put into effect along the mathematical solution process, but also the complexity of arithmetic-algebraic knowledge entwined in the elementary algebraic reasoning tasks. Jacobs et al., (2007) consider that an emphasis on mathematics content and on structure could be fundamental for the learning of teachers (p. 285).

As a conclusion, we can state that our research shows that the counselling given to preservice teachers foster the partial "algebrafying" of some exercises; nonetheless it did little to sensitize them in regard to the relational character of the equal sign. It seems that the preservice teachers have broadened their comprehension on elementary algebraic reasoning, what allows them to recognise and to question some algebraic features of mathematical activities, nonetheless this recognising and questioning is still done in the frame of secondary algebraic reasoning.

We consider that, in order for the preservice teachers to develop "eyes and ears" to recognise and to foster algebraic reasoning in elementary school, answers have to be provided to the following questions: How does integrate numeric and algebraic knowledge recognising arithmetic structure as the base for algebra?; How integrate students conceptions into a more wide view of algebra?; Which are the meeting points between arithmetic, algebra and elementary algebraic reasoning?

The answers to these questions could be used to design preservice teachers' education programs that include and emphasize the development of planning competences aimed to foster elementary algebraic reasoning. Such education programs should expand the limited conception that the preservice teachers exhibit on algebra and integrate some characteristics belonging to mathematical reasoning: language elements, concepts, properties, procedures and justifications.

\section{Acknowledgements}

This research work has been carried out partially in the frame of the project EDU201231869. Ministerio de Economia y Competitividad (MINECO, España).

\section{Authors}

Walter F. Castro-G., Professor of Mathematics Education, School of Education, University of Antioquia. calle 67 No. 53 - 108. Medellin, Antioquia, Colombia; wfcastro82@gmail.com 
Juan D. Godino, Professor of Mathematics Education, Graduate School of Education, University of Granada, Cartuja Campus. P.C 18071- Granada Spain; jgodino@ugr.es

\section{REFERENCES}

Anderson, J. R. (2002). Spanning seven orders of magnitude: A challenge for cognitive modeling. Cognitive Science, 26, 85-112.

Asquith, P., Stephens, A., Knuth, E., \& Alibali, M. (2007). Middle school mathematics teachers' knowledge of students' understanding of core algebraic concepts: equal sign and variable. Mathematical Thinking and Learning, 9(3), 249-272.

Ball, D., Thames, M. H., \& Phelps, G. (2008). Content knowledge for teaching: What makes it special? Journal of Teacher Education, 59(4), 430-511.

Bastable, V., \& Schifter, D. (2007). Classroom stories: Examples of elementary students engaged in early algebra. In J. J. Kaput, D. W. Carraher \& M. L. Blanton (Eds.), Algebra in the early grades. Mahwah, NJ: Lawrence Erlbaum Associates.

Bednarz, N., \& Janvier, B. (1996). Emergence and development of algebra as a problem solving tool:continuities and discontinuities with arithmetic. In N. Bednarz, C. Kieran \& L. Lee (Eds.), Approaches to algebra (pp. 115-136). Dordrecht, The Netherlands: Kluwer Academics.

Bell, A. W. (1996). Problem-solving approaches to Algebra:Two aspects. In N. Bednarz, C. Kieran \& L. Lee (Eds.), Approaches to Algebra. Perspectives for Research and Teaching (pp. 167-186). Dordrecht/Boston/London: Kluwer Academic Press.

Behr, M., Erlwanger, S., \& Nichols, E. (1980). How children view the equal sign. Mathematics Teaching, 92, 13-15.

Blanton, M. L., \& Kaput, J. J. (2001). Algebrafying the elementary mathematics experience Part II. In H. Chick, K. Stacey, J. Vincent \& J. Vincent (Eds.), The future of the teaching and learning of algebra (Vol. 1, pp. 87-102). Melbourne: University of Melbourne, Australia.

Blanton, M. L., \& Kaput, J. J. (2003). Developing elementary teachers" "algebra eyes and ears.". Teaching Children Mathematics, 10, 70-77.

Blanton, M. L., \& Kaput, J. J. (2005). Characterizing a classroom practice that promotes algebraic reasoning. Journal for Research in Mathematics Education, 36(5), 412-446.

Booth, L. R. (1984). Algebra: Children's strategies and errors. A report of the strategies and errors in secondary mathematics project. Windsor, Berkshire: Nfer-Nelson.

Borko, H., Pittman, M., Eiteljorg, E., Nelson, M., \& Jacobs, J. (2005). Preparing teachers to foster algebraic thinking. ZDM The International Journal on Mathematics Education, 37(1), 43-52.

Borko, H., \& Shavelson, R. (1990). Teacher decision making. In B. F. Jones \& L. Idol (Eds.), Dimensions of thinking and cognitive instruction (pp. 311-346). Hillsdale,NJ: Lawrence Erlbaum.

Boulton-Lewis, G. M., Cooper, T. J., Atweh, H. P., Wilss, L., \& Mutch, S. (1997). The transition from arithmetic to algebra: a cognitive perspective. In E. Pehkonen (Ed.), 21th International Group for the Psychology of Mathematics Education (Vol. 2, pp. 185192). Latki, Finland.

Burkhardt, H. (2001). Algebra for all: What does it mean? How are we doing? In H. Chick, K. Stacey, J. Vincent \& J. Vincent (Eds.), The future of the teaching and learning of algebra (Vol. 1, pp. 140-146). Melbourne: University of Melbourne, Australia.

Carpenter, T. P., \& Franke, M. L. (2001). Developing algebraic reasoning in the elementary school: generalization and proof. In H. Chick, K. Stacey, J. Vincent \& J. Vincent (Eds.), Proceeding of the 12th ICMI Study Conference. The Future of the Teaching and Learning of Algebra (Vol. 1, pp. 155-162). Melbourne: University of Melbourne.

Carpenter, T. P., Franke, M. L., \& Levi, L. (2003). Thinking mathematically: Integrating arithmetic and algebra in the elementary school. Portsmouth, NH:Heinemann

Carpenter, T. P., \& Levi, L. (2000). Developing conceptions of algebraic reasoning in the primary grades Retrieved February 24, 2006, from http: / /www.mth.msu.edu/cmp.

Carraher, D. W., Martinez, M., \& Schliemann, A. (2008). Early algebra and mathematical generalization. ZDM The International Journal on Mathematics Education, 4O(1), 322.

Carraher, D. W., \& Schliemann, A. (2007). Early algebra and algebraic reasoning. In F. K. Lester (Ed.), Second Handbook of Research on Mathematics Teaching and Learning (Vol. 2, pp. 669-705). Reston: NCTM. 
Chevallard, Y. (1989). Le passage de l'arithmétique à l’algébrique dans l'enseignement des mathématiques au collége. Petit $x, 5,51-94$.

Clement, J. (1982). Algebra word problem solution through process underlying a common misconception. Journal for Research in Mathematics Education, 3(1630).

Cooney, T. J. (1985). A beginning teacher's view of problem solving. Journal for Research in Mathematics Education, 16, 324-336.

Cooper, T. J., Williams, A. M., \& Baturo, A. R. (1999). Simplifying algebraic expressions, Proceedings of the 1999 annual conference of the Australian Association for the Research in Education. Melbourne.

English, L., \& Warren, E. (1998). Introducing the variable through pattern exploration. The Mathematics Teacher, 91(2), 166-171.

Ferrero, L; I, Gaztelou; Luelmo, M.J; Martin, P y Martinez, L.(2007) Matemáticas para sexto grado. Editorial Anaya.

Filloy, E., \& Rojano, T. (1989). Solving equations: the transition from arithmetic to algebra. For the Learning of Mathematics, 9(2), 19-25.

Filloy, E., Rojano, T., \& Rubio, G. (2001). Propositions concerning the resolution of arithmetic-algebraic problems. In $R$. Sutherland, T. Rojano, A. Bell \& R. Lins (Eds.), Perspectives on School Algebra (pp. 155-176). Dordrecht, The Netherlands: Kluwer Academic.

Freiman, V., \& Lee, L. (2004). Tracking primary student's understanding of the equality sign. In H. M. J. \& A. B. Fuglestad (Eds.), Proceedings fo the International Group for the Psychology of Mathematics Education. Bergen, Norway.

Godino, J. D., Batanero, C., \& Font, V. (2007). The ontos-semiotic approach to research in mathematics education. ZDM The International Journal on Mathematics Education, 19(1-2), 127-135.

Herscovics, N., \& Kieran, C. (1980). Constructing meaning for the concept of equation. Mathematics Teacher, 73(8), 572-580.

Jacobs, V., Franke, M. L., Carpenter, T. P., Levi, L., \& Battey, D. (2007). Professional development focused on children's algebraic reasoning in elementary school. Journal for Research in Mathematics Education, 38(3), 258-288.

Kaput, J. J. (1998). Transforming algebra from an engine of inequity to an engine of mathematical power by 'algebrafying' the $K$ 12 curriculum. Paper presented at the The nature and role of algebra in the K-14 curriculum, Washington, D.C.
Kieran, C. (1981). Concepts associated with the equality symbol. Educational Studies in Mathematics, 12(3), 317-326.

Kieran, C., \& Chalouh, L. (1993). The transition from arithmetic to algebra. In T. D. Owens (Ed.), Research ideas for the classroom: Middle grades mathematics (pp. 179-198). New York: MacMillan

Knuth, E., Stephens, A., McNeil, N., \& Alibali, M. (2006). Does understanding the equal sign matter? Evidence from solving equations. Journal for Research in Mathematics Education, 37(4), 297-312.

Kücheman, D. (1981). Algebra. In K. Hart (Ed.), Children's understanding of mathematics: 1116 (pp. 102-119). London: John Murray.

Linchevski, L., \& Livneh, D. (1999). Structure sense: the relation between algebraic and numerical contexts. Educational Studies in Mathematics, 4O(173-196).

MacGregor, M., \& Price, E. (1999). An exploration of aspects of language proficiency and algebra learning. Journal for Research in Mathematics Education, 30(4), 449-467.

Mason, J., Pimm, D., Graham, A., \& Gower, N. (1985). Routes to/Roots of Algebra: Milton Keynes:Open University.

McGowen, M. A., \& Davis, G. (2001). Changing preservice elementary teachers ${ }^{\prime}$ attitudes to algebra. In H. Chick, Stacey, J. Vincent \& J. Vincent (Eds.), Proceedings of the 12th ICMI Study Conference: The Future of the Teaching and Learning of Algebra (Vol. 2, pp. 438-446). University of Melbourne, Australia.

McNeil, N., \& Alibali, M. (2002). A strong schema can interfere with learning: The case of children's typical addition schema. In C. D. Schunn \& W. Gray (Eds.), Proceedings of the Twenty-Fourth Annual Conference of the Cognitive Science Society (pp. 661-666): Mahwah, NJ: Erlbaum.

McNeil, N., \& Alibali, M. (2004). You'll see what you mean: Students encode equations based on their knowledge of arithmetic. Cognitive Science, 28, 451-466.

McNeil, N., \& Alibali, M. (2005). Why Won`t You Change Your Mind? Knowledge of Operational Patterns Hinders Learning and Performance on Equations. Child Development, 76(4), 883-899.

McNeil, N., Grandau, L., Knut, E., Alibali, M., Stephens, A., Hattikudur, S., et al. (2006). Middle-School Students'Understanding of the Equal Sign: The Books They Read Can't Help. Cognition and instruction, 24(3), 367385. 
Nathan, M., \& Koedinger, K. (2000). An investigation of teachers ' beliefs of students ${ }^{-}$ algebra development. Cognition and Instruction, 18(2), 209-237.

MEC (2006). Real Decreto 1513/2006, BOE number 293

Nesher, P., \& Teubal, E. (1975). Verbal cues as an interfering factor in verbal problem solving. Educational Studies in Mathematics, 6(1), 41-51.

Puig, L., \& Cerdan, F. (1990). Acerca del caracter aritmético o algebraico de los problemas verbales. In E. Filloy \& T. Rojano (Eds.), Simposio Internacional sobre Investigación en Educación Matemática (pp. 35-48). Cuernava: Morelos:PNFAPM.

Rojano, T. (1988). Teaching equation solving: A teaching experiment with a concretesyntactic approach. In M. Behr, C. Lacampagne \& M. Wheeler (Eds.), Tenth International Group for the Psychology of Mathematics Education. North American Chapter (pp. 150-156). Dekalb, Illinois.

Schifter, D. (1999). Reasoning about operations: Early Algebraic Thinking, Grades $\mathrm{K}$ through 6. In L. V. Stiff \& F. Curio (Eds.), Mathematical Reasoning, K-12:1999 NCTM Yearbook (pp. 62-81). Reston, VA: National Council of Teachers of Mathematics.

Sfard, A. (1991). On the dual nature of mathematical conceptions: reflections on processes and objects as different sides of the same coin. Educational Studies in Mathematics, 22(1), 1-36.

Simon, M. A., \& Blume, G. W. (1994). Building and Understanding Multiplicative Relationships: A Study of Preservice Elementary Teachers. Journal for Research in Mathematics Education, 25(5), 472-494.

Sinha, S. M. (2006). Mathematical Programming:Theory and methods: Elsevier Inc.

Stephens, A. (2008). What "counts" as algebra in the eyes of preservice elementary teachers? Journal of Mathematical Behavior, 27, 33-47.

Stump, S. L., \& Bishop, J. (2002). Preservice elementary and middle school teachers' conceptions of algebra revealed throuhg the use of exemplary curriculum materials. In
D. S. Mewborn, P. Sztajn, D. Y. White, H. G. Wiegel, R. L. Bryant \& K. Nooney (Eds.), Proccedings of the Twenty-Fourth annual meeting of the International group for the psychology of mathematics education (pp. 1903-1914). Columbus, $\mathrm{OH}$.

Subramaniam, K., \& Banerjee, R. (2004). Teaching arithmetic and algebraic expressions. In M. Johnsen \& A. Berit (Eds.), Proceedings of the 28th International Group for the Psychology of Mathematics Education (Vol. 3, pp. 121-128). Bergen, Noruega.

Van Dooren, W., Vershaffel, L., \& Onghema, P. (2003). Preservice teachers's preferred strategies for solving arithmetic and algebra word problems. Journal of Mathematics Teacher Education, 6(27-52).

Warren, E. (2005). Young children's ability to generalize the pattern rule for growing patterns. In H. Chick \& J. Vincent (Eds.), 29 th conference of the International Group for the Psychology of Mathematics Education (Vol. 4, pp. 305-312). Melbourne:University of Melbourne.

Williams, A. M., \& Cooper, T. J. (2001). Moving from arithmetic to algebra under the time pressures of real classrooms. In H. Chick, K. Stacey, J. Vincent \& J. Vincent (Eds.), Proceedings fo the 12th ICMI Study Conference: The future of the Teaching and Learning of Algebra (Vol. 2, pp. 665-662). Melbourne: University of Melbourne.

\section{$\diamond \diamond \diamond$}

\section{Citation Suggestions :}

APA : Castro-Gordillo, W.F; Godino, J.D (2014). Preservice elementary teacher's thinking about algebraic reasoning. Mathematics Education, 9(2), 147-162. 